\title{
Determination of the kinetics of ethene epoxidation
}

\author{
E.P.S. Schouten, P.C. Borman, K.R. Westerterp* \\ Chemical Reaction Engineering Laboratories, Department of Chemical Engineering, University of Twente, PO Box 217, \\ 7500 AE Enschede, Netherlands
}

Received 22 February 1995; accepted 24 April 1995

\begin{abstract}
Several problems and pitfalls in the use of laboratory reactors for the determination of the kinetics of ethene epoxidation over industrial silver on $\alpha$-alumina catalyst are discussed. Also, commonly used methodologies for kinetic studies are dealt with because of the general nature of some problems. Some advice is given in choosing and using the appropriate reactor type. Further, a method is discussed to determine kinetics in a cooled tubular reactor without having to use heat transport relations.

The activation and deactivation of the silver catalyst have been studied in a Berty-type reactor, in a novel internal recycle reactor and in a cooled tubular reactor. It was found necessary to activate the silver catalyst for approximately 170 reaction hours uncer reaction conditions to obtain a stable and reproducible catalyst activity. Thermal sintering was probably of importance in experiments at the maximum temperature of $543 \mathrm{~K}$. Deliberate addition of small amounts of 1,2-dichloroethane resulted in rapid deactivation of the catalyst. The activity could be restored by addition of small amounts of ethane to the feed. Also, fluorine and silica have been shown to poison the catalyst. Differences in the behaviour of the catalyst in the three reactors may be attributed to the sensitivity of the catalyst towards tiny amounts of poisons present in the reactors and feed mixtures used.
\end{abstract}

Keywords: Kinetic reactors; Selective oxidation of ethene; Activation; Deactivation

\section{Introduction}

Knowledge of the kinetics of the reactions occurring is an essential aspect in the design and the operation of many reactors. Different types of laboratory reactors have been developed for the determination of the kinetics of solid-catalysed gas phase reactions, all with their specific advantages and disadvantages $[1-6]$.

A typical example of such a reaction is the selective oxidation of ethene to ethene oxide, carried out industrially in a wall-cooled packed-bed reactor. This reaction is catalysed by silver on an alumina carrier. The most important side reaction is the highly exothermic, total combustion of ethene to carbon dioxide and water [7]. It is necessary to know precisely the kinetics of both reactions to describe the reactor selectivity and thermal behaviour accurately.

* Corresponding author.
In our laboratories we have studied the kinetics of the ethene epoxidation in specific reactors for determining the reaction kinetics. Problems and pitfalls using laboratory reactors for this particular reaction system will be dealt with. Some of the problems encountered are of a general nature and in our opinion their importance is not always sufficiently recognized in the literature. Therefore we will start by discussing commonly used methods for the determination of kinetics and will pay attention to issues found to be relevant for ethene epoxidation. In a different article [8], literature on ethene epoxidation is discussed and the obtained reaction rate expressions are given.

\section{Kinetic studies}

Reaction rates are determined in laboratory reactors at varying operating conditions to develop a suitable kinetic model. In the following we will distinguish several steps in the translation of kinetic experiments into adequate reaction rate expressions. This leads to 
the formulation of demands to be imposed on kinetic experiments. Next, we will give a survey of available laboratory reactors and discuss them on the basis of the demands given. Further, a method is discussed which allows for translation of cooled tubular reactor data to kinetic data.

\subsection{Determination of kinetics}

The following steps can be distinguished in the determination of kinetic equations:

(1) determination of reaction rates at varying operating conditions;

(2) development of a mathematical model for the kinetic reactor;

(3) development of a number of possible reaction rate expressions;

(4) determination of parameter values in a kinetic model on the basis of the experiments;

(5) choice of the "best" kinetic model.

In particular the influence of temperature and partial pressures of reactants and products on reaction rates is studied experimentally. Experimental design can be helpful to vary these parameters systematically and to reduce the required number of experiments. The kinetic reactor model must be simple for a convenient interpretation of the experiments. Reaction rate equations should be based on (quasi-) mechanistical principles, in which elementary steps of chemical adsorption, desorption and reaction are distinguished and rate-determining step is identified [5]. A large number of kinetic expressions based on possible reaction mechanisms should be tested for their ability to describe accurately the experimentally found reaction rates. Parameter values in the kinetic expressions are obtained by fitting to the experimental data. The choice for a "best" kinetic rate expression can be made on the basis of the accuracy of the fit of rival kinetic models. In practice this may be difficult because often kinetic expressions, based on different mechanisms, describe experimental data with more or less equal accuracy [9-11]. In addition no single, objective criterion is available to determine which model is best.

The following demands must be imposed on kinetic experiments to obtain a correct and accurate description of the rates as a function of the major operating variables.

- Measured rates should not be disguised by internal or external mass and/or heat transport limitations $[12,13]$.

- Flow patterns in the reactor should be known and be incorporated in the reactor model.

- Studies in different reactors types should be compatible: homogeneous reactions, reactions influenced by the reactor construction material or poisoning of the catalyst should not take place.
- Experiments must be done at relevant conditions because extrapolation of kinetic data may lead to large errors or deviations from real values [10.14].

- Kinetic experiments should be reproducible.

- Effects of temperature, of primary reactants and of product inhibition should be determined separately in different experimental series [15].

- Sampling must be possible without disturbing the system.

- Operation and maintenance of the equipment must be easy.

In addition it is preferred that

- the state of mixing in the kinetic reactor is known and like ideal plug flow or gradientless conditions,

- the system is isothermal and isobaric, and

- experimental design is possible.

The influence of catalyst deactivation on the compatibility of different studies is not always recognized. Therefore we will make some remarks on this. Catalysts in industrial production plants are exposed to more or less constant reaction conditions during a life cycle. In laboratory reactors, on the contrary, reaction conditions are varied rapidly over broad ranges and may become so severe that deactivation is a serious problem. In addition, poisoning of the catalyst by construction materials can occur more easily, because the ratio of catalyst material to construction material is smaller for laboratory reactors. It should also be recognized that the distribution of poison over catalyst material may not be the same for each type of reactor: because of the flow pattern in for example an industrial fixed-bed reactor the poison will accumulate in the first part of the catalyst bed, while in an ideally mixed laboratory reactor the poison will be distributed uniformly over the bed.

\subsection{Laboratory reactors for the determination of kinetics}

Several laboratory reactor types have been developed. The most important for the determination of the kinetics of solid catalysed reactions are briefly discussed here.

In pulse reactors a sudden change in an operating parameter such as reactant concentration or feed temperature is made. The response of the catalyst to the pulse is measured. Sometimes also intermediates on a catalyst surface are identified. This method may be appropriate to determine the reaction mechanism but it does not give much quantitative information because continuously changing partial pressures over the length of the catalytic column and adsorption on the catalyst make interpretation of data difficult.

In batch reactors ideal mixing is easy to achieve. The reactor is cheaper than a continuous reactor. It has a high flexibility in chemicals used, catalyst particle sizes 
Table 1

Comparison of different laboratory reactors for the determination of kinctics

\begin{tabular}{|c|c|c|c|c|c|c|c|}
\hline Reactor type & $\begin{array}{l}\text { Ease of } \\
\text { operation }\end{array}$ & $\begin{array}{l}\text { Ease of } \\
\text { analysis }\end{array}$ & $\begin{array}{l}\text { Relevant } \\
\text { conditions }\end{array}$ & $\begin{array}{l}\text { Ease of } \\
\text { interpretation }\end{array}$ & $\begin{array}{l}\text { Separate } \\
\text { determination } \\
\text { of parameters }\end{array}$ & $\begin{array}{l}\text { Ideal flow } \\
\text { pattern }\end{array}$ & Remarks \\
\hline Pulse & + & 0 & - & - & - & 0 & Only qualitative information \\
\hline Batch & + & - & 0 & 0 & - & + & High flexibility \\
\hline Differential & 0 & - & + & + & + & - & Limited conversions \\
\hline Integral & 0 & + & + & - & - & 0 & $\begin{array}{l}\text { Temperature and concentration } \\
\text { gradients }\end{array}$ \\
\hline Recycle & 0 & + & 0 & + & 0 & + & Accuracy dependent on recycle ratio \\
\hline Tubular reactor ${ }^{\mathrm{a}}$ & - & 0 & + & 0 & + & 0 & $\begin{array}{l}\text { Measurement of temperature and } \\
\text { concentration in bed }\end{array}$ \\
\hline
\end{tabular}

+ , good; 0 , irrelevant or average; - , bad.

anterpretation with development method.

and reaction times. Taking samples may constitute a problem if the amounts withdrawn influence the results obtained. The reactor is not suitable for fast reactions. Separation of the influence of individual factors is difficult, in particular of reaction kinetics and possible deactivation [16].

Continuous differential reactors are run with short residence times so conversions are usually low and concentration and temperature gradients small. High analytical accuracies are required and plug flow must be ensured.

In continuous integral reactors longer residence times are applied. Conversions are larger and concentration and temperature gradients in both axial as well as in radial direction are more pronounced. Accuracy requirements for chemical analysis are relaxed. Interpretation of data is more difficult and possibly inaccurate, because of less well-defined conditions. Such reactors must be operated isothermally and in plug flow.

Recycle reactors consist of a fixed catalyst bed over which the reaction mixture is recycled, either externally or internally. External recycling is necessary for highly exothermic rapid reactions and is combined with cooling or heating the recycle stream to maintain a constant temperature over the reactor and/or to protect recycle equipment. In internal recycle reactors the catalyst is for example placed in a basket [3], and the gas is circulated by an impeller over the catalyst bed. In Ref. [2] the catalyst was positioned on the wall of the reactor. The catalyst phase can also be rotated $[1,6]$. The fact that any conversion can be obtained and concentration and/or temperature gradients are absent at high recycle ratios, like in an ideal tank reactor, make this reactor an attractive tool for kinetic studies.

Usually considerable amounts of products are present in a recycle reactor, so it is difficult to cover the entire range of relevant product concentrations. Experimental design cannot be applied a priori because the effect of a change in inlet conditions is not known until the kinetics has been determined. This problem is often underestimated. A possible solution deserving attention is to adjust the inlet conditions until the desired outlet concentration is achieved [17]. This requires control of the mass flow to the reactor for each component independently and a method to vary the flows in such a way that eventually the desired outlet concentration is obtained. According to Ref. [15] this also requires addition of products to the feed, otherwise systematically biased rate expressions may be obtained.

The effect of a certain reaction product may be disguised because other products are also present in the reaction mixture. In Ref. [17] an attempt is made to avoid this by performing a series of kinetic experiments in a recycle reactor at different mass flow rates but at fixed inlet compositions. Concentrations will equal the inlet composition if the mass flow rate is infinitely large, so the reaction rate at inlet conditions can be obtained by extrapolation of the experimentally obtained values. The effect of one specific product can be studied in the absence of other products by addition of that particular product to the reactor feed. This method needs much experimental work for only one data point, and therefore a systematic and complete study of the influence of all components is hardly possible.

The magnitude of the recycle ratio in the reactor is important to ensure the absence of temperature and/or concentration gradients. It is not always realized that a recycle ratio high enough to give perfect mixing behaviour in tracer response experiments does not ensure perfect mixing under reacting conditions; see also Appendix A. It is hardly possible to determine the recycle ratio directly [10]. An indirect alternative is to check experimentally that no significant gradients are present. Differences between catalyst temperature and gas temperature indicate that the flow inside the catalyst bed is not high enough to prevent external heat transport resistances while a difference between temperature at inlet and outlet indicates that mixing in the reactor is not ideal. 
The various aspects of kinetic reactors are summarized in Table 1. A simultaneous use of two or more different kinetic reactors may be advantageous in many cases, because experiments can be executed in different operating regimes and also reaction rates obtained in experiments in different reactor types at the same conditions can be compared. If the rates are not equal, falsification of data or catalyst deactivation may have occurred.

\subsection{Translation of cooled tubular reactor data into kinetic data}

Kinetic data at inlet conditions can be obtained in an isothermal integral reactor by measuring the conversion over the bed at varying space velocities $F^{0} / \mathrm{W}$ [18]. In Ref. [12] a survey of this method is given which has successfully been employed by Frankaerts and Froment [19] to determine the kinetics of the dehydrogenation of ethanol. The initial reaction rates in the catalyst bed are determined by extrapolating the experimentally obtained conversion vs. $W / F^{0}$ curves to a zero residence time:

$R^{0}\left[\frac{\mathrm{d} x}{\mathrm{~d}\left(W / F^{0}\right)}\right]_{W / F^{0}=0}$

In Ref. [19] experimental $\mathrm{d} x / \mathrm{d}\left(W / F^{0}\right)$ data have been evaluated with Newton's interpolation method. Systematic and separate variations in pressure and feed composition give the desired orthogonality, meaning that the effect of each parameter can be determined independently without interference of concurrent changes in other parameters. In addition to "pure" feed in which only reactants are present they also have used "mixed" feed, containing reactants and products. This way of analysing kinetic data can be qualified as a differential evaluation of integral reactor data [5]. Also here experiments at several mass flow rates have to be conducted for only one data point. An alternative approach is to measure the axial concentration profile in the catalyst bed. The amount $W$ of catalyst over a length $z$ can be expressed as

$W=\rho_{\mathrm{b}} A_{\mathrm{t}} z$

Substitution of Eq. (2) into Eq. (1) results in

$R_{0}=\frac{F^{0}}{\rho_{\mathrm{b}} A_{\mathrm{t}}}\left(\frac{\mathrm{d} x}{\mathrm{~d} z}\right)_{z=0}$

Thus the initial reaction rate can be determined in one single experiment by differentiating the conversion vs. axial position curve at $z=0$. In the special case of the selective oxidation of ethene two reactions occur, so two equations are necessary. The following equations can easily be derived from mass balances for ethene and carbon dioxide:

$$
\begin{aligned}
& \left(\frac{\mathrm{d} x_{\mathrm{E}}}{\mathrm{d} z}\right)_{z=0}=-\frac{\rho_{\mathrm{b}} R T^{0}}{v_{\mathrm{s}} P^{0}}\left(R_{1}^{0}+\frac{1}{2} R_{2}^{0}\right) \\
& \left(\frac{\mathrm{d} x_{C}}{\mathrm{~d} z}\right)_{z=0}=\frac{\rho_{\mathrm{b}} R T^{0}}{v_{\mathrm{s}} P^{0}} R_{2}^{0}
\end{aligned}
$$

where $v_{s}$ is the superficial gas velocity at $z=0$. The gas is assumed to be in plug flow; volume changes because of reaction, pressure drop and internal and external mass transfer resistances are neglected. In addition, reaction rates at the inlet are assumed to be constant over the radius. If the reactor operates isothermally and $T^{0}=T_{\mathrm{w}}$ this is ensured. Also, for changing axial temperatures this method is applicable provided that the radial temperature profile at the inlet is flat. In that case there is no driving force for radial transport of heat, so the axial temperature gradient at the inlet can be expressed as follows:

$$
\left(\frac{\mathrm{d} T}{\mathrm{~d} z}\right)_{z=0}=-\frac{\rho_{\mathrm{b}}}{\left(\rho c_{\mathrm{p}}\right)_{\mathrm{g}} v_{\mathrm{s}}}\left(R_{1}^{0} \Delta H_{1}+\frac{1}{2} R_{2}^{0} \Delta H_{2}\right)
$$

if axial dispersion of heat and internal and external heat transport resistances are absent. The temperature and concentration gradients at the inlet can be evaluated by extrapolation of experimental data to the inlet. An example is given in Fig. 1. Use of any two of the three equations (4), (5) and (6) is sufficient to obtain $R_{1}$ and $R_{2}$. The third equation can be used as a check. Rate data obtained should not depend on the radial position chosen provided that the bed is really adiabatic. However, after the inlet, radial profiles develop and heat is transported in radial direction to the wall. Extrapolation of measured temperatures and concentrations to the inlet will become difficult and inaccurate if a large amount of heat is transported in that direction.

The method described has the following advantages.

- Kinetic experiments are carried out with the same gases and in the same apparatus as used in other studies. Thus differences in catalyst activity between studies in different reactors are avoided.

- Kinetic data can be obtained at low concentrations or in absence of reaction products. This is almost impossible in recycle studies.

- Inlet conditions of temperature and concentration can be changed systematically and independently. In contrast to recycle studies, experimental design can be applied easily for this type of experiment.

Disadvantages are that

- a flat temperature profile at the inlet is necessary,

- axial dispersion of heat and mass and external and internal resistances for heat and mass should be negligible, and

- axial temperature and concentration profiles must be measured accurately. 


\section{Ethene epoxidation}

Numerous kinetic studies have been published on the epoxidation reaction of ethene over silver on $\alpha$ alumina catalyst $[8,11,20-23]$. There is no general agreement on the mechanism of the reactions. In Refs. $[8,11]$ several rival kinetic models have been tested on the basis of their own experimental work. The parameters in the kinetic expressions have been determined with the statistical SIMUSOL ${ }^{\mathrm{tm}}$ package. A dual-site Langmuir-Hinshelwood type reaction rate expression has been chosen as the best kinetic model in both studies. All reaction products are observed to adsorb competitively on the active sites and to inhibit the reaction rates. For a detailed discussion of the existing literature we refer to Ref. [8]. Here we will only discuss some causes of the deactivation of the silver catalyst because of their relevance for explaining the results.

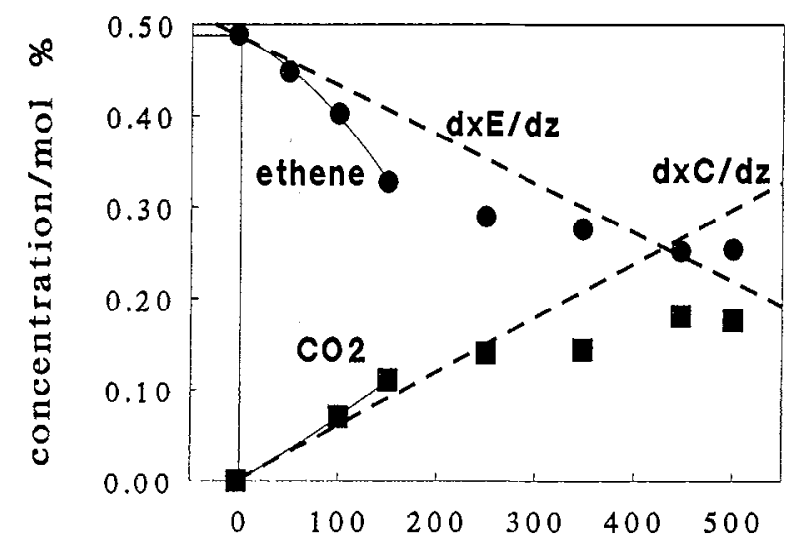

(a)

axial position $/ \mathrm{mm}$

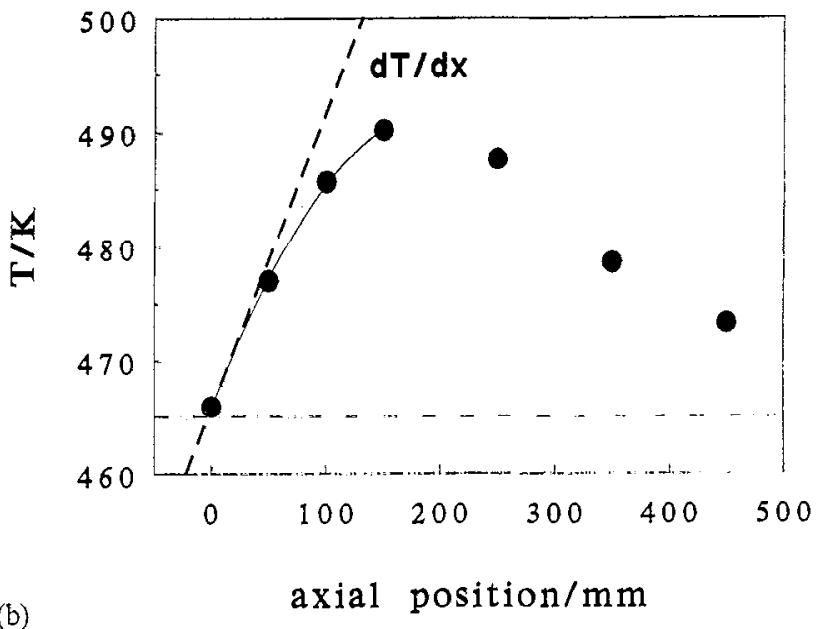

Fig. 1. Polynomial approximation (a) of the concentration profiles for ethene and carbon dioxide and (b) for the axial temperature profile. Conditions are $P=0.5 \mathrm{MPa}, T_{\mathrm{w}}=465 \mathrm{~K}$, $\phi_{\mathrm{m}}=0.83 \mathrm{~kg} \mathrm{~m}^{-2} \mathrm{~s}^{-1}$ and $x_{\mathrm{E}, \mathrm{m}}=0.5 \mathrm{~mol} \%$. The slopes at $z=0$ are also shown.

\subsection{Deactivation of the silver catalyst}

At higher temperatures the catalyst will deactivate because of sintering. In our case, silver atoms or silver oxide molecules become mobile and form larger clusters with a reduced activity [16]. A high temperature in combination with a high concentration of carbon dioxide also leads to deactivation because of irreversible deposition of carbonates on the catalyst surface [24].

The small active surface area of the silver catalyst of around $1 \mathrm{~m}^{2} \mathrm{~g}^{-1}$ makes it very sensitive to poisoning. Elements more electronegative than oxygen such as selenium, sulphur, chlorine and fluorine become bound to the catalyst surface and lower the bond strength of reactive oxygen on the surface [22]. Gas phase concentrations in the order of a few parts per million of the elements mentioned already decrease the catalyst activity [25-28]. At even lower concentrations of these elements more favourable conditions are obtained, because the selectivity towards ethene oxide increases, although at the same time the activity decreases. This is known as "selective poisoning" of the catalyst. In industrial practice some chlorine-containing component such as $\mathrm{HCl}$ is deliberately added to the reactor feed. 1,2-dichloroethane (DCE) is also often used because it decomposes into, inter alia, $\mathrm{HCl}$, which is adsorbed on the catalyst surface [29]. In some publications it is claimed that the amount of chlorine adsorbed on the surface is influenced by the presence of a scavenger in the gas phase [29]. This scavenger probably promotes the removal of chlorine atoms from the catalytic surface, so larger concentrations of chlorine can be used without the catalyst activity being reduced.

\section{Experimental details}

In our experimental work the reactions are carried out with ethene in an excess of air and industrial silver on $\alpha$-alumina Raschig ring as catalyst. No details of the catalyst formulation will be given because of confidentiality reasons. The catalyst particle has an outer diameter of around $8.4 \mathrm{~mm}$, an inner diameter of around $3.0 \mathrm{~mm}$ and a height of around $8.5 \mathrm{~mm}$. The effective diameter, defined as $6 V_{\mathrm{p}} / A_{\mathrm{p}}$, is $6.15 \mathrm{~mm}$ and the mean density of the porous particles is $1800 \mathrm{~kg} \mathrm{~m}^{-3}$.

\subsection{Equiment}

Three reactors have been used to determine the kinetics of the ethene oxidation: an internal recycle reactor with a design similar to that in Ref. [3], a new type of gradientless reactor we have developed in our laboratories, also known as the Bobo reactor [6], and a cooled tubular reactor [30]. A brief description of each reactor will follow. 


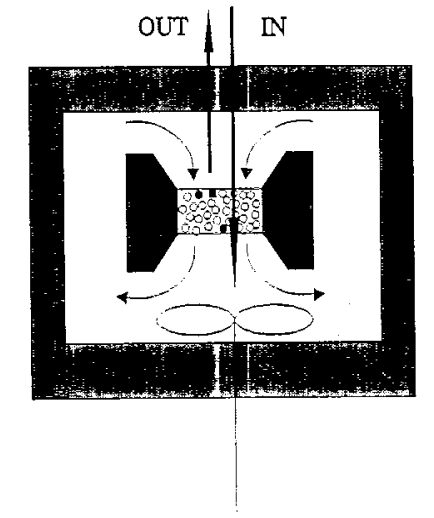

(a)

(b)

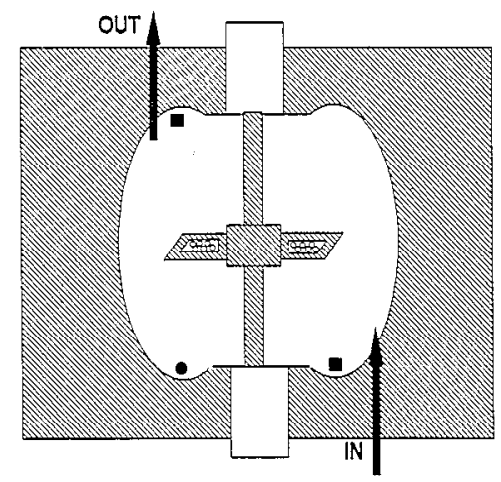

(c)

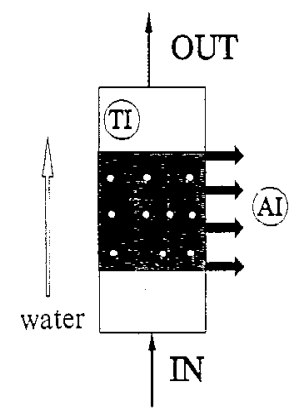

Fig. 2. The three reactors used for the determination of the reaction kinetics: $\mathbf{\square}, O$, location of gas temperature sensor; $\boldsymbol{\bullet}$, location of catalyst temperature sensor; $\rightarrow$, sample point; (a) the Berty-type internal recycle reactor; (b) the novel perfectly mixed Bobo reactor; (c) the cooled tubular reactor.

\section{Berty-type recycle reactor}

Catalyst particles with a total mass of $40.2 \mathrm{~g}$ have been placed in a baskct positioned in the middle of a 0.51 reactor (Fig. 2(a)). A magnetically driven impeller in the bottom of the reactor recycles the gas over the catalyst bed. Catalyst pellet temperatures at the inlet and the outlet of the catalyst bed are measured to check for possible temperature gradients over the bed [30]. The gas temperature at the inlet has been measured with a third thermocouple to check whether interphase heat transport resistances are present. Temperature differences between the inlet and the outlet of the bed and between catalyst and gas never have exceeded $2 \mathrm{~K}$ in all our experiments. The rotational speed of the impeller is limited to $1800 \mathrm{rev} \mathrm{min}^{-1}$. The magnitude of the recycle gas flow is unknown [10].

\section{Bobo recycle reactor}

A novel perfectly mixed reactor has been developed in our laboratories to avoid the mechanical problems pertinent to Berty-type reactors and possible falsification of the obtained reaction rate expressions because of too low recycle ratios [6]. Perfect mixing is achieved by circulating the gas in a well-streamlined enclosure with an axial flow impeller (Fig. 2(b)). The impeller has bearings in both the top and the bottom part of the reactor. The catalyst pellets are fixed between grids in rectangular openings in the impeller blades. Velocity differences between catalyst and gas are large and consequently external heat and mass transport is fast. On each of the three blades only a limited number of catalyst particles can be placed. Another catalyst particle is fixed on a K-type thermocouple located in the housing near the wall to measure catalyst temperatures under worse transfer conditions than in the impeller itself. Two other thermocouples measure the gas temperature in the reactor. The volume of the apparatus is approximately 3.31 and in our experiments 19 pellets with a total mass of $12.9 \mathrm{~g}$ have been used.

\section{Cooled tubular reactor}

Experiments have been performed in a packed tube with an internal diameter of $53 \mathrm{~mm}$ (Fig. 2(c)). The tube is packed with catalyst over a length of about $0.50 \mathrm{~m}$. The concentration and the radial temperature profiles are measured at several axial locations in the tube. Inert layers have been placed before and after the catalyst bed to ensure that temperature and velocity profiles in the catalyst bed are fully developed. Excess air is mixed with ethene, preheated and led to the catalyst bed in the tube and cooled via the wall by boiling water under pressure. The wall temperature remains uniform over the entire length of the bed in all experiments. The installation has becn designed in such a way that the bed inlet temperature profile is flat and equal to the wall temperature.

\subsection{Reactor feed}

Premixed gases, consisting of air and ethene, have been used in an early stage of our kinetic studies. After some contradictory results using gas of different sources, it has been decided to purify ambient air and further to use pure ethene as supplied in bottles [8]. The purified air has a dew point below $0^{\circ} \mathrm{C}$, contains less than $3 \mu \mathrm{g} \mathrm{m}^{-3}$ of oil and does not contain particles larger than $0.01 \mu \mathrm{m}$. Carbon dioxide and other contaminants if present could not be detected. The ethene has a purity of $99.9 \mathrm{~mol} \%$. In Table 2 the composition of the ethene is given. We once analysed a bottle of ethene and found a concentration of $182 \mathrm{ppm}$ ethane and less than $10 \mathrm{ppm}$ acetylene. If idle, the reactors are flushed permanently at reaction temperature with $99.999 \mathrm{~mol} \%$ 
Table 2

Composition of the ethene used in the kinetic studies as supplied by Hoek Loos

\begin{tabular}{lc}
\hline Ethene & $99.9 \mathrm{~mol} . \%$ \\
Methane + ethane & $<700 \mathrm{ppm}$ \\
Acetylene & $<50 \mathrm{ppm}$ \\
Carbon dioxide & $<20 \mathrm{ppm}$ \\
Water & $<10 \mathrm{ppm}$ \\
Oxygen & $<5 \mathrm{ppm}$ \\
Carbon monoxide & $<2 \mathrm{ppm}$ \\
\hline
\end{tabular}

nitrogen. The concentrations of ethene and carbon dioxide in the feed and in the effluent have been measured with a gas chromatograph and the carbon dioxide concentration also on line with an IR spectrometer.

The concentration of reaction products varies with the conversion; the partial pressures of carbon dioxide and water always remain strictly equal to each other if they are not already added to the feed, because at combustion each molecule of ethene converted to $\mathrm{CO}_{\text {2 }}$. and $\mathrm{H}_{2} \mathrm{O}$ yields two molecules of both products. In certain experiments $\mathrm{CO}_{2}$ of a purity of $99.97 \mathrm{~mol} \%$ has been added to the feed to vary the ratio of $\mathrm{CO}_{2}$ to $\mathrm{H}_{2} \mathrm{O}$. In the cooled tubular reactor vaporized demineralized water, carbon dioxide and/or ethene oxide have been added to the feed to study separately the influence of each product. Experiments with addition of ethene oxide have not been successful as reported in Ref. [8].

In some experiments to study poisoning we have added small amounts of DCE as a model substance to the feed using a low capacity mass flow controller regulating the flow of a nitrogen stream containing 100 ppm DCE. During periods of reactor idleness it has been ensured that DCE is present in the same concentration as at reaction conditions by adding DCE to the nitrogen. The concentrations of DCE used in the kinetic experiments have been 0.07 and $0.10 \mathrm{ppm}$.

\subsection{Interpretation of kinetic data}

The activity of the catalyst in the three reactors has been regularly checked at intervals by performing a standard cxperiment. Both recycle reactors are considered to be isothermal and ideally mixed for the interpretation of the data. Falsification of data occurs if the real conditions in the kinetic reactors deviate from the conditions assumed in the reactor model. In Appendix A we show that falsification may occur in our case because of temperature gradients over the calalyst bed.

The kinetic data of the cooled tubular reactor have been interpreted with the method discussed before. Temperatures and concentrations measured in the centre of the tube at the inlet, at $z=50 \mathrm{~mm}$ and at $z=100 \mathrm{~mm}$ are used to derive second-order polynomial equations to approximate the axial profiles (see Fig. 1). These equations are differentiated analytically with re- spect to $z$ and the derivative at $z=0$ is calculated to be used in Eqs. (4) and (6) for determining the reaction rates. The results obtained with Eq. (5) are used for comparison only because the analytical accuracy of the $\mathrm{CO}_{2}$ concentration is low.

\section{Results and discussion}

\subsection{Activation of the catalyst}

The catalyst activity must be stable and reproducible for kinetic experiments. Therefore one large batch of catalyst has been activated as long as necessary to reach a stable activity and selectivity. The activation procedure consists of operating the cooled tubular reactor at a wall temperature of $465 \mathrm{~K}$, a reactor pressure of $0.5 \mathrm{MPa}$, a concentration in the feed of $0.8 \mathrm{~mol} \%$ ethene and a mass flux of $0.83 \mathrm{~kg} \mathrm{~m}^{-2} \mathrm{~s}^{-1}$. We determine the reactor conversion and selectivity as a function of time at the beginning and the end of each day. The catalyst particles have been mixed after reaching a steady state and have been used in all our kinetic experiments. This ensures compatibility of the catalyst for the different kinetic studies. Two more batches have been activated in the same way to check whether the activation procedure is reproducible: results are shown in Figs. 3(a) and 3(b). On the vertical axis the moving averages of the conversion and the selectivity respectively are shown; this average is taken of each experimental result and the four previous experimental results. Initially the activity and selectivity decrease; then the activity slowly increases and eventually reaches a final conversion level of about 0.40 after about $170 \mathrm{~h}$ and a selectivity of about 0.60 already after about $75 \mathrm{~h}$. There is no difference between the three activated batches within the experimental error; the steady state is reached somewhat later in activation 2. Sometimes the activity increases after a period of reactor idleness and flushing with nitrogen but most of the time the activity remains the same between experiments.

Pretreatment methods have not been discussed in sufficient detail in literature to allow a comparison, as already mentioned in Ref. [21]. In the following we will discuss available information on pretreatment. In Refs. $[27,31]$ only a high sensitivity of their catalyst to the method of preparation and of pretrealment'was reported. In Ref. [32] the authors treated a commercial silver catalyst for approximately $150 \mathrm{~h}$ before they started the measurements. They exposed the catalyst for $10 \mathrm{~h}$ to oxygen at $573 \mathrm{~K}$ and flushed the system with nitrogen at room temperature followed by $10 \mathrm{~h}$ of reaction and repeated this procedure for 10 consecutive days. Next the catalyst is treated for another $24 \mathrm{~h}$ with oxygen at $573 \mathrm{~K}$. After flushing the system again with nitrogen, a reaction mixture is fed to the catalyst con- 


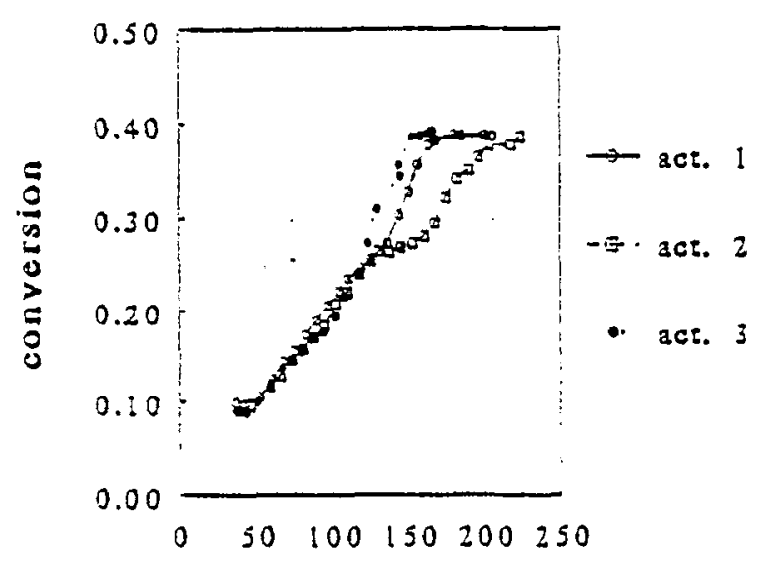

(a)

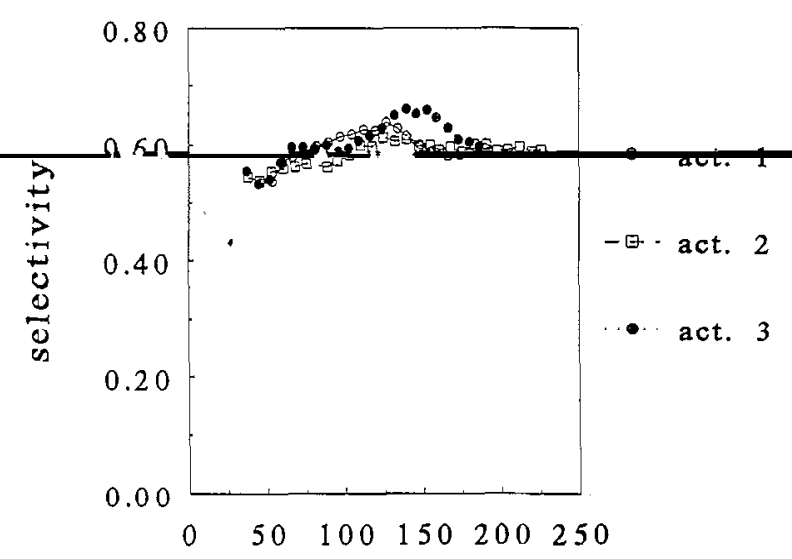

(u)

time/hour

Fig. 3. (a) Conversion and (b) selectivity over the catalyst bed vs. time during the activation of the catalyst at $T_{\mathrm{w}}=465 \mathrm{~K}, P=0.5 \mathrm{MPa}$, $x_{\mathrm{E}, \text { in }}=0.8 \mathrm{~mol} \%$ and $\phi_{\mathrm{m}}=0.83 \mathrm{~kg} \mathrm{~m}^{-2} \mathrm{~s}^{-1}$. The experimental points have been averaged with a moving average technique.

taining 4 mol.\% ethene and $8 \mathrm{~mol} . \%$ oxygen with the balance being nitrogen; the conversion has been observed to increase in an oscillatory way from $6 \%$ after $2 \mathrm{~h}$ to $46 \%$ after $106 \mathrm{~h}$. In Ref. [33] several activation procedures were studied. In one experiment the authors exposed the catalyst to pure oxygen at $523 \mathrm{~K}$, flushed with nitrogen and pretreated with different concentrations of ethene. The pretreated catalyst exhibits an initial reduction in activity, followed by a gradual rise to a steady state in a few hours. In Ref. [22] a steady state was obtained in $7 \mathrm{~h}$ by treating a fresh catalyst with a reaction mixture at a temperature of $533 \mathrm{~K}$.

We suppose during activation that deposits of chemicals used in catalyst preparation, such as amines, may be removed, promoters distributed more uniformly over the catalyst surface and silver transformed to the proper oxidation state. However, we cannot explain why it is necessary to condition the catalyst for such a long time in our case.

The results of the kinetic experiments are reported in Ref. [8]. Regretfully kinetic parameter values differ in the fitting to the three data sets obtained in the three different kinetic reactors. Fitting of all data simultaneously results in much larger average errors and to deviating tendencies in parity plots. To some extent the discrepancies may be explained by a different range of partial pressures covered in the experimental series in the different reactors. Another reason might be the deactivation of the catalyst during some of our kinetic experiments: if we compare experiments in the cooled tubular reactor at equal operating conditions measured successively in time (Fig. 4), it can be observed that the maximum temperature in the reactor becomes lower and shifts further downstream into the reactor. This observation may be attributed to deactivation of the catalyst. Within the experimental error conversions over the reactor remain almost unchanged which may be explained by locally higher reaction rates further in the deactivated bed in view of higher ethene concentrations.

In the follnwing sestion some tests wil he discusses which we have done to study possible deactivation

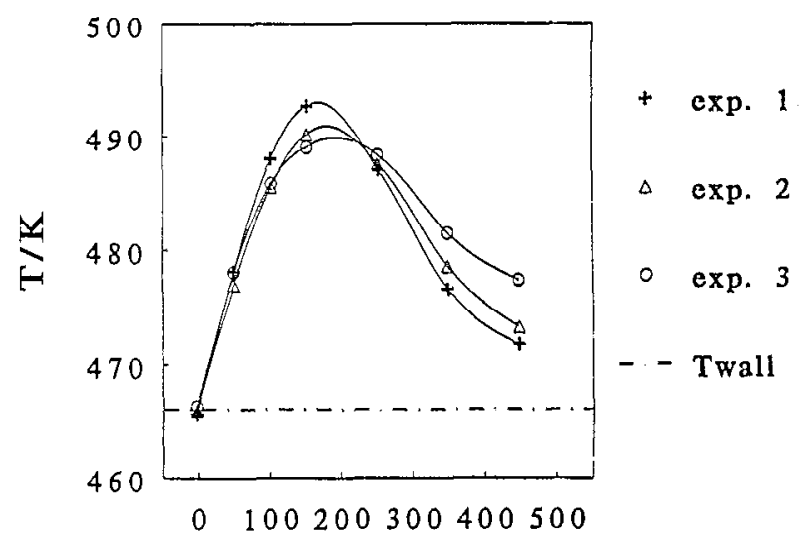

(a)

axial position $/ \mathrm{mm}$

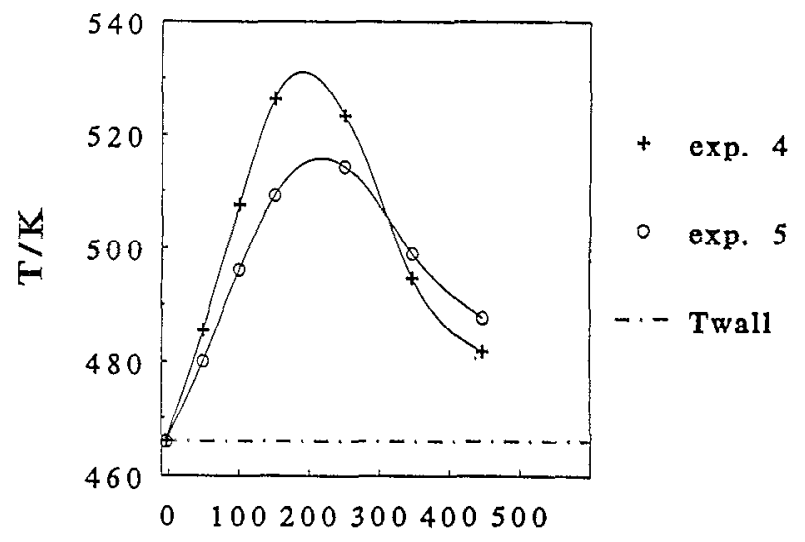

(b)

axial position/mm

Fig. 4. Catalyst temperatures in the axis of the cooled tubular reactor at (a) $0.5 \mathrm{~mol} \%$ and (b) $0.9 \mathrm{~mol} \%$ ethene concentration in the feed. Conditions were $T_{\mathrm{w}}=466 \mathrm{~K}, \phi_{\mathrm{m}}=0.83 \mathrm{~kg} \mathrm{~m}^{-2} \mathrm{~s}^{-1}$ and $P=0.5 \mathrm{MPa}$. The numbering is in the sequence of time: exp. 5 has therefore been executed after exp. 4, exp. 3 after exp. 2 and exp. 2 after exp. 1. 
behaviour of the catalyst. In the course of our kinetic study we also encountered some cases in which the catalyst appeared to be sensitive to the presence of certain undesired components in the reactor. We will also report on these cases.

\subsection{Deactivation of the catalyst}

We exposed the catalyst in the Berty-type recycle reactor to higher temperatures for a longer period. A temperature of $543 \mathrm{~K}$ was chosen as this is the maximum allowable temperature in the cooled tubular reactor: even higher temperatures will damage the temperature-resistant plastic spokes of the thermocouple frame inside the cooled tubular reactor [30]. Both at reaction conditions as well as at idleness under flushing with nitrogen, a temperature of $543 \mathrm{~K}$ was maintained in the Berty reactor. In the course of an experiment the composition of the reaction mixture changed although the inlet concentrations remained fixed which must be attributed to a gradually decreasing catalyst activity. This changing composition has an influence on the reaction rates. To separate the effect of the changing composition from the effect of the deactivation itself we have plotted in Fig. 5(a) on the vertical axis the ratio of the experimentally obtained reaction rate and the reaction rate calculated with the obtained kinetic rate expression on the basis of the measured reaction mixture composition. Thus we correct the reaction rates for the changing reaction mixture composition and, by doing so, are able to attribute the decrease in the defined ratio to only deactivation of the catalyst. The reaction rates drop about $25 \%$ in the first $50 \mathrm{~h}$, after which a much smaller decline for the epoxidation reaction is found and an almost stable reaction rate for the total combustion reaction. There are two possible explanations for the deactivation: sintering can be expected to occur both at reaction conditions as well as during periods of idleness, while irreversible deposition of carbonates will only occur during reaction. The scatter in the experimental results in Fig. 5(a) is so large that it cannot be determined which of the two explanations is correct.

The catalyst has been shown to be sensitive to fluorine: after start-up of the Bobo reactor an activity decrease has been observed both at reaction conditions as well as during periods of idleness, which excludes deactivation by contaminants in the feed (see Fig. 5(b)). Traces of fluorine have been detected on the catalyst surface which most probably originate from a Teflon ${ }^{\text {tm }}$ gasket. We assume this fluorine to poison the catalyst. After changing to a copper gasket no such decline occurred any more.

In other experiments the catalyst is also deactivated but only at reaction conditions (Fig. 5(c)). Small silica particles have been found on the catalyst surface, probably originating from a molecular sieve installed ini- tially in the feed system to clean the air. The molecular sieve has been removed and a filter system consisting of two oil filters, a dust filter, an adsorption dryer and an active coal filter have been installed; for further details, see Ref. [30]. In Fig. 5(d) the conversion and selectivity are shown as measured during the gathering of kinetic data: the deactivation is much smaller than in Figs. $5(\mathrm{a}), 5(\mathrm{~b})$ and $5(\mathrm{c})$ although still a small decrease in conversion can be observed.

Deliberate addition of small amounts of DCE also leads to catalyst deactivation in the Berty type recycle reactor (see Fig. 5(e)) and simultaneously to a selectivity increase. No steady state could be reached before full deactivation. This is in contrast to the literature, where a steady state activity at larger concentrations of DCE than we used has been observed in, for example, Refs. $[28,29]$. We did not succeed in restoring the catalyst activity after stopping the DCE supply and feeding a standard reaction mixture of air and ethene over the catalyst. A possible explanation might be that the ethene we use has a composition different from industry and probably also from other studies. In particular, the absence of ethane may be important because ethane has been described as a chlorine scavenger [34]. The same explanation was given in Ref. [34] for problems in an industrial ethene oxide process in which very pure ethene was used: control problems and a catalyst deactivation at moderate concentrations of DCE might also be explained by the absence of ethane. To check this hypothesis we have poisoned the catalyst in the Bobo recycle reactor with chlorine to a level of $50 \%$ activity decrease and regenerated with a standard reaction mixture containing $0.1 \mathrm{~mol} \%$ ethane and no DCE (see Fig. $5(\mathrm{f})$ ). The catalyst activity has been fully restored within $60 \mathrm{~h}$. Thus ethene probably strips chlorine from the catalytic surface. Moreover, the final catalyst activity to carbon dioxide and water became even higher than $100 \%$ of the original activity. We may explain this by some amount of poison present on the catalyst surface already at the start of the experiment, which is also removed by ethane and would not necessarily be chlorine. So some amount of poison may also have been present in one or more reactors during the kinetic study and influenced the kinetic expressions which have been obtained. This may be an explanation for the discrepancies which have been found between the kinetic studies performed in the different laboratory reactors [8].

\section{Conclusions and recommendations}

Conclusions are given regarding the determination of kinetics of heterogeneously catalysed reactions in general as well as to the selective oxidation of ethene.

No laboratory reactor is ideal for dctcrmining kinctics. In each particular case the best kinetic reactor 

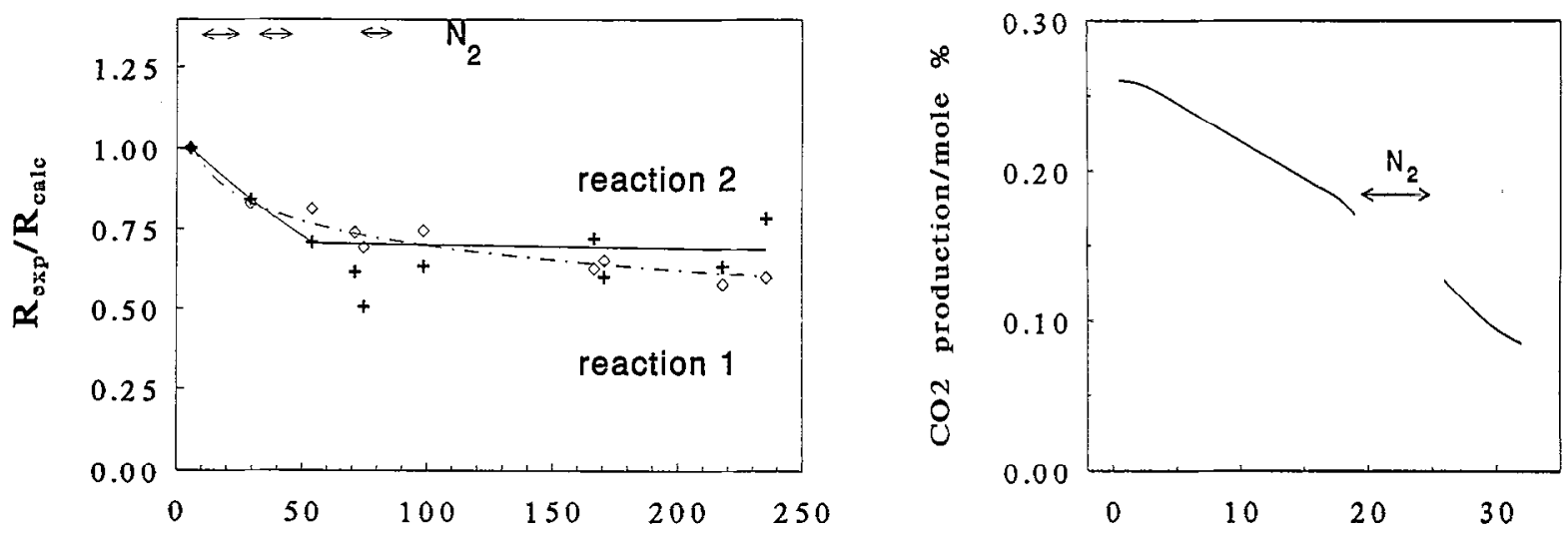

(a)

time/hour

(b)

time/hour

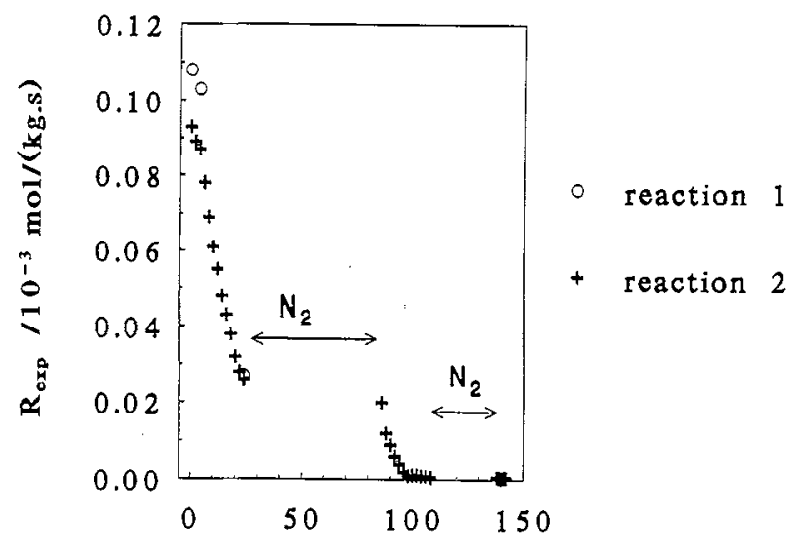

(c)

time/hour

(d)
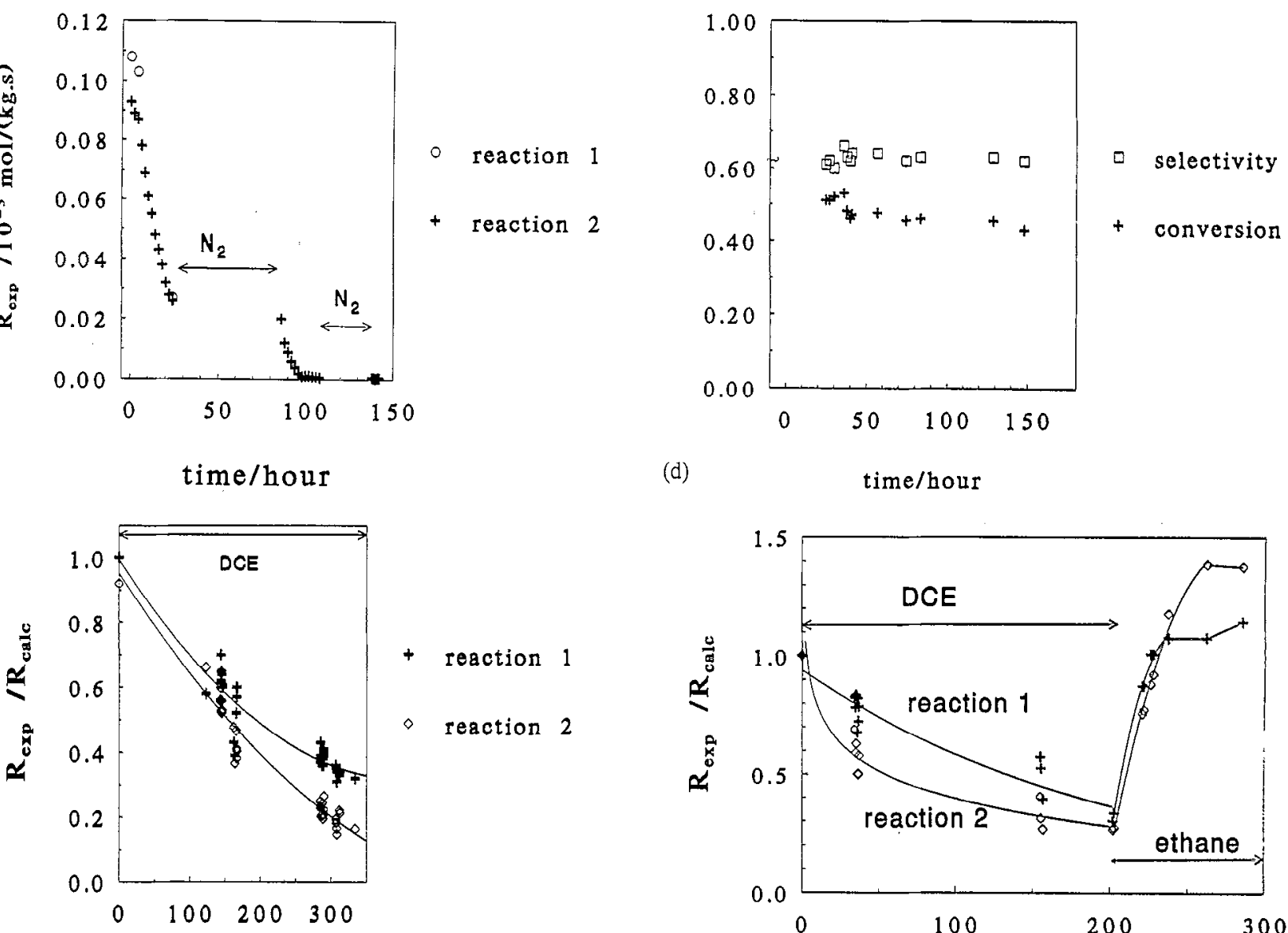

(e)

time/hour

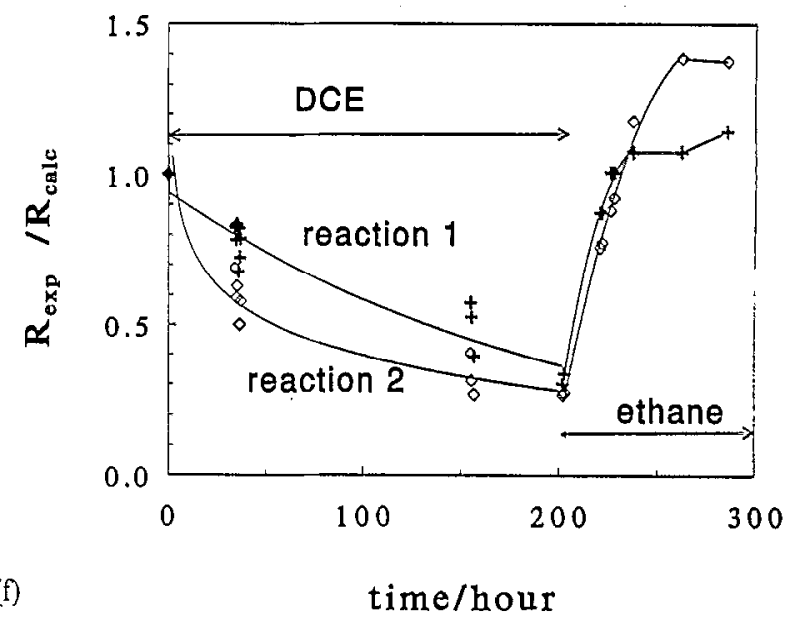

Fig. 5. Deactivation of the silver catalyst for the oxidation of ethene. (a) Reaction rates for ethene epoxidation and total combustion reaction in the Berty reactor vs. time. Deactivation has occurred possibly as a result of thermal sintering or irreversible deposition of carbon dioxide. (b) Carbon dioxide production in the Bobo reactor vs. time. Deactivation has occurred possibly as a result of poisoning with fluorine. (c) Reaction rates for ethene epoxidation and total combustion reaction in the Bobo reactor vs. time. Deactivation has occurred possibly as a result of poisoning with silica. (d) Conversion and selectivity in the Berty reactor vs. time at the following inlet conditions: $P=0.5 \mathrm{MPa}, T=476 \mathrm{~K}$, $x_{\mathrm{E}, \mathrm{in}}=0.9 \mathrm{~mol} \%$ and $F=0.75 \times 10^{-3} \mathrm{~mol} \mathrm{~s}^{-1}$. (e) Reaction rates for ethene epoxidation and total combustion reaction in the Berty reactor with the addition of $0.10 \mathrm{ppm}$ DCE to the feed. (f) Reaction rates for ethene epoxidation and total combustion reaction in the Bobo reactor with the addition of $0.07 \mathrm{ppm}$ DCE to the feed, followed by addition of $0.1 \mathrm{~mol} \%$ ethane to the feed.

should be chosen carefully depending on considerations such as heat effect of the reactions, sensitivity of the catalyst for poisoning, operating regime, flow patterns in the reactor, ease of interpretation of data, possibility to determine the influence of parameters separately and possibility of experimental design. Sometimes a combi- 
nation of reactors should be considered because the operating regime may be enlarged and to check for falsification of data and/or catalyst deactivation. In many cases a recycle reactor is the appropriate choice provided that the recycle ratio is high enough. If this reactor type is used we advise control of the outlet conditions. This can be achieved by adjusting the feed flows of reactants and products independently. We also advise measurement of temperatures of the catalyst at the inlet and outlet as well as the gas temperature. Falsification of data will occur if significant gradients are present. Further, a method has been discussed to obtain kinetics from cooled tubular reactor data. The main advantage of the method is it allows for a systematic study of the influence of a parameter without interference with concurrent changes in other parameters.

The silver catalyst we used for the ethene epoxidation has to be activated for about $170 \mathrm{~h}$ before the activity becomes constant. Poisoning of the catalyst was found to occur by the presence of fluorine, silica and small concentrations of DCE in the reactor. A considerable deactivation has been found at the maximum temperature of $543 \mathrm{~K}$ although the activity decrease became much smaller after a period of $50 \mathrm{~h}$. The presence of small concentrations of ethane was found to reverse the deactivation caused by DCE, possibly because it strips chlorine from the catalyst surface. A possible continuation would be to add ethane during the kinetic experiments to make the catalyst less sensitive to poisoning. An aspect still to be studied is whether the kinetics with addition of ethane would be identical in case no ethane is added. A considerable effort had to be put into checking the inertness of materials in the experimental set-up and the possible presence of poisons in feed streams. Discrepancies may still be obtained in results from different reactors because of the large sensitivity of the catalyst to a very small concentration of contaminants.

\section{Acknowledgements}

The technical assistance of K.v. Bree, F.t. Borg, A.H. Pleiter and O.D. Veehof, and the experimental work of F. Luikinga, M.T.A.M. Molenaar, J.H. Hendriks, W.F. Hendriksen and B. Hendriks are gratefully acknowledged. The authors also would like to thank the Royal Dutch Shell Group for supplying the catalyst and the International Shell Group for performing catalyst analyses.

\section{Appendix A: Falsification of kinetic data obtained in a recycle reactor for the ethene epoxidation}

The presumed absence of temperature and concentration gradients in internal recycle reactors makes the interpretation of experimental data easy when compared with data determined in tubular reactors. However, if the recycle ratio in an internal recycle reactor is too low, temperature and concentration gradients may develop over the catalyst bed, leading to errors if an interpretation is made as if no gradients were present. We define a falsification ratio $f$ as the ratio between the actual reaction rate and the reaction rate according to the outlet conditions in the kinetic reactor. For exothermic reactions the reaction rate in the catalyst bed changes as a result of the increase in temperature and the decrease in concentrations along the length of the bed. The actual reaction rate is an average of the local reaction rates in the catalyst bed (Fig. A1). For no gradients in the bed this averaging will yield the same reaction rate as at the outlet and $f$ will equal 1 , according to

$f \equiv \frac{\frac{1}{\zeta_{\mathrm{b}}} \int_{\zeta_{\text {out }}-\zeta_{\mathrm{b}}}^{\zeta_{\text {out }}} R(\zeta) \mathrm{d} \zeta}{R_{\text {out }}}$

$\zeta_{b}$ is the conversion over the catalyst bed. This conversion $\zeta_{b}$ can be calculated if the total conversion $\zeta_{\text {out }}$ and the recycle ratio $R R$ are known:

$\zeta_{b}=\frac{1}{\left[\left(1-\zeta_{\text {out }}\right) / \zeta_{\text {out }}\right] R R+1}$

For $R R=1$ the bed conversion equals the total conversion and the recycle reactor operates as an integral reactor, while for $R R=\infty$ the bed conversion becomes zero and the reactor is truly perfectly mixed.

In the case of the ethene oxidation two falsification ratios are defined: one for the epoxidation reaction and one for the total combustion reaction. Calculated falsification ratios $f_{i}$ in an internal recycle reactor for a feed consisting of $1.0 \mathrm{~mol} \%$ ethene in air are given in Fig. A2. Conditions are a pressure of $0.5 \mathrm{MPa}$ and an outlet temperature of $500 \mathrm{~K}$. Kinetics and parameter values for the physical constants can be found in Ref. [30]. The falsification ratio $f$ is lower than 1 for lower conversions because the temperature increases over the catalyst bed. This effect is more pronounced for reaction 2 as caused by the higher activation energy. The falsification ratio also may be-

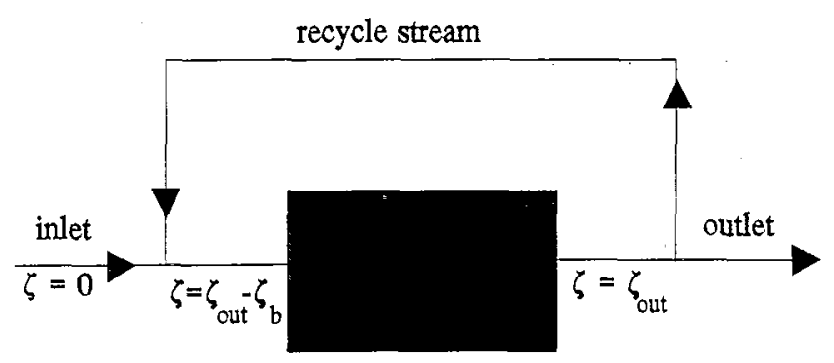

Fig. A1. Schematic representation of an internal recycle reactor. 


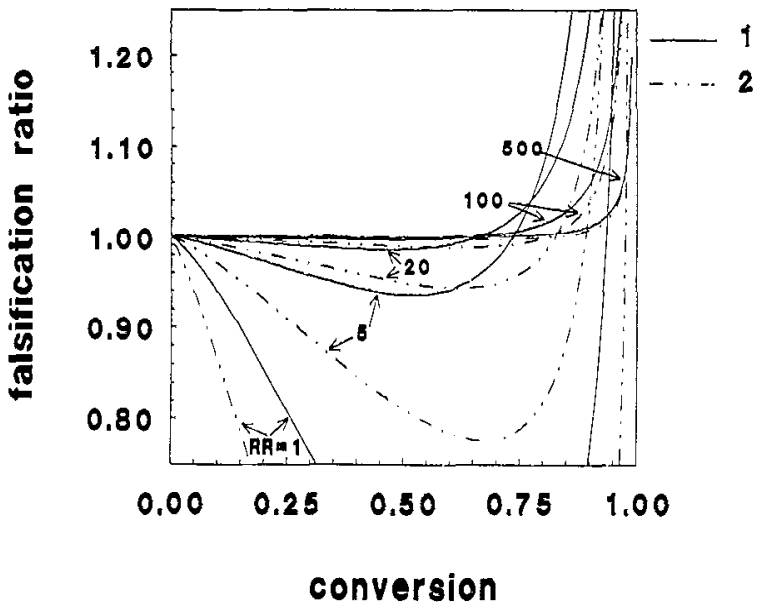

Fig. A2. Falsification ratio in an internal recycle reactor for the ethene epoxidation for the following conditions: $x_{E, i_{n}}=1.0 \mathrm{~mol} \%$, $P=0.5 \mathrm{MPa}$ and $T_{\text {out }}=500 \mathrm{~K}$; curves 1 , epoxidation; curves 2 , total combustion.

come larger than 1 , because the reaction mixture composition gives higher reaction rates at the entrance of the bed than at the outlet. This effect is dominating over the effect of temperature at higher conversions.

We have estimated the recycle flow rate for the Bobo reactor and for the Berty-type reactor, yielding recycle flow rates of $2.8 \times 10^{-3} \mathrm{~m}^{3} \mathrm{~s}^{-1}$ and $1.4 \times$ $10^{-4} \mathrm{~m}^{3} \mathrm{~s}^{-1}$ respectively; see Ref. [6]. These values give only an order of magnitude because no good empirical relations are available for determining the recycle flow. A representative inlet flow rate is about $1.0 \mathrm{~N}^{-1} \mathrm{~min}^{-1}$, so recycle ratios are about 500 in the Bobo reactor and 25 in the Berty reactor for the conditions as mentioned before. In Fig. A2 it can be seen that for these recycle ratios conversions must be kept below 0.97 for the Bobo reactor and below 0.80 for the Berty reactor.

\section{Appendix A: Nomenclature}

$\begin{array}{ll}A & \text { area }\left(\mathrm{m}^{2}\right) \\ f & \text { falsification ratio } \\ F & \text { molar flow rate }\left(\mathrm{mol} \mathrm{s}^{-1}\right) \\ \Delta H & \text { heat of reaction or of adsorption }\left(\mathrm{J} \mathrm{mol}^{-1}\right) \\ P & \text { pressure }(\mathrm{Pa}) \\ R & \text { production rate }\left(\mathrm{mol} j \text { produced }(\mathrm{s} \mathrm{kg} \mathrm{catalyst})^{-1}\right) \\ R & \text { gas constant }\left(8.31 \mathrm{~J}(\mathrm{~mol} \mathrm{~K})^{-1}\right) \\ \mathrm{RR} & \text { recycle ratio } \\ T & \text { temperature }(\mathrm{K}) \\ v_{\mathrm{s}} & \text { superficial velocity }\left(\mathrm{m} \mathrm{s}^{-1}\right) \\ W & \text { amount of catalyst }(\mathrm{kg}) \\ x & \text { mole fraction } \\ z & \text { axial coordinate }(\mathrm{m})\end{array}$

Greek symbols

$\zeta$ conversion

$\rho$ density $\left(\mathrm{kg} \mathrm{m}^{-3}\right)$

$\phi_{\mathrm{m}} \quad$ mass flux $\left(\mathrm{kg}\left(\mathrm{m}^{2} \mathrm{~s}\right)^{-1}\right)$

Subscripts and superscripts

b bed

C carbon dioxide

calc calculated

$E$ ethene

exp experimental

g gas

in inlet

$j$ of component $j$

out outlet

$t$ tube

w wall

0 inlet conditions

1 epoxidation reaction

2 total combustion reaction

\section{References}

[1] J.J. Carberry, Designing laboratory reactors, Ind. Eng. Chem., 56 (1964) $39-46$.

[2] F.E. Ford and D.D. Perlmutter, The kinctics of the brass-catalyzed dehydrogenation of sec-buty! alcohol, Chem. Eng. Sci, 19 (1964) $371-378$.

[3] J.M. Berty, Reactors for vapour-phase catalytic studies, Chem. Eng. Proc., 70 (1974) 78-84.

[4] V.W. Weekman, Laboratory reactors and their limitations, AIChE J., 20 (1984) 833-840.

[5] E.G. Cristoffel, Laboratory reactors and heterogeneous catalytic processes, Catal. Reu. Sci. Eng., 24 (1982) 159-232.

[6] P.C. Borman, A.N.R. Bos and K.R. Westerterp, A novel reactor for determination of kinetics for solid catalysed reactions, AIChE J., 40 (1994) 862-869.

[7] I.J. Berty, J.M. Berty, P.T. Brinkerhoff and T. Chovan, Testing catalysts for production performance and runaway limits, $I n d$. Eng. Chem. Res., 28 (1989) 1589-1596.

[8] E.P.S. Schouten, P.C. Borman and K.R. Westerterp, Influence of reaction products on the selective oxidation of ethene, Chem. Eng. Proc., in press.

[9] J.M. Berty, The state of kinetic model development, Chem. Eng. Prog., (1988) 61-67.

[10] A.N.R. Bos, E.S. Bootsma, F. Foeth, H.W.J. Sleijster and K.R. Westerterp, A kinetic study of the hydrogenation of ethyne and ethene on a commercial $\mathrm{Pd} / \mathrm{Al}_{2} \mathrm{O}_{3}$ catalyst, Chem. Eng. Proc, 32 (1993) 53-63.

[11] P.C. Borman and K.R. Westerterp, An experimental study of the kinetics of the selective oxidation of ethene over a silver on $\alpha$-alumina catalyst, Ind. Eng. Chem. Process Des. Dev., to be published.

[12] G.F. Froment, Model discrimination and parameter estimation in heterogeneous catalysis, $A I C h E J_{.}, 21$ (1975) 1041-1057.

[13] H. Hofmann, Kinetic data analysis and parameter estimation, in Chemical Reactor Design and Technology, NATO ASI Series, Applied Sciences, Vol. 110, 1987, pp. 69-105. 
[14] K.S. Bej and M.S. Rao, Selective oxidation of $n$-butane to maleic anhydride. 4. Recycle reactor studies, Ind. Eng. Chem. Res., 31 (1992) 2075-2079.

[15] J.B. Cropley, Systematic errors in recycle reactor kinetic studies, Chem. Eng. Prog., (February 1987) 46-51.

[16] J.-F. Le Page, H.V. Landeghem and J. Limido, Applied Heterogeneous Catalysis: Design, Manufacture, Use of Solid Catalysts, Technip, Paris, 1987.

[17] W. Bremer, Untcrsuchungen zum Einfluß der periodischen Prozeßführung auf das Temperaturfeld im Festbettreaktor, Ph.D. Thesis, TH Clausthal, Jülich, 1982.

[18] K.H. Yang and O.A. Hougen, Determination of mechanism of catalyzed gaseous reactions, Chem. Eng. Prog., 46 (1950) 146157.

[19] J. Frankaerts and G.F. Froment, Kinetic study of the dehydrogenation of ethanol, Chem. Eng. Sci., 19 (1964) 807-818.

[20] P.L. Metcalf and P. Harriott, Kinetics of silver-catalyzed ethylene oxidation, Ind. Eng. Chem. Process Des. Dev., 11 (1972) 478-484.

[21] X.E. Verykios, F.P. Stein and R.W. Coughlin, Oxidation of ethylene over silver: adsorption, kinetics and catalyst, Catal. Rev. Sci. Eng., 22 (1980) 197-234.

[22] R.A.v. Santen and H.P.C.E. Kuipers, The mechanism of the ethylene epoxidation, Adv. Catal., 35 (1987) 265-321.

[23] M.A. Al-Saleh, M.S. Al-Ahmadi and M.A. Shalabi, Kinetic study of ethylene oxidation in a Berty reactor, Chem. Eng. J., 73 (1988) 35-41.

[24] I.E. Wachs and S.R. Kelemen, The interaction of ethylene with surface carbonate and hydroxide intermediates on silver, $J$. Catal., 71 (1980) 78-87.

[25] J.T. Kummer, The catalytic oxidation of ethylene to ethylene oxide over single crystals of silver, J. Phys., 60 (1956) 666-670.

[26] M.M. Voge and C.R. Adams, Catalytic oxidation of olefins, Adv. Catal., 17 (1967) 151-211.

[27] M.I. Temkin, Ihe kinetics of some industrial heterogeneous catalytic reactions, Adv. Catal., 28 (1979) 173-190.

[28] L. Petroy, A. Eliyas and D. Shopov, Kinetics of ethylene oxidation over a silver catalyst in the presence of di-chloro ethane, Appl. Catal., 24 (1986) 145-161.

[29] G.L. Montrasi and G.C. Battiston, Oxidation of ethylene to ethylene oxide: role of organic chlorides, Oxid. Commun., 3 (1983) 259-267.

[30] E.P.S. Schouten, P.C. Borman and K.R. Westerterp, Oxidation of ethene in a wall cooled packed bed reactor, Chem. Eng. Sci., to be published.

[31] A. Orzechowski and K.E. MacCormack, Can. J. Chem., 32 (1954) $388-443$.

[32] S.V. Dhalewadikar, E.N. Martinez and A. Varma, Complex dynamic behaviour during ethylene oxidation on a supportcd silver catalyst, Chem. Eng. Sci., 41 (1987) 1743-1746.

[33] L.G. Nault, D.W. Bolme and L.N. Johanson, Reaction rate studies of catalytic oxidation of ethylene, Ind. Eng. Chem. Process Des. Dev., I (1962) 285-292.

[34] J.M. Berty, Inhibitor action of chlorinated hydrocarbons in oxidation of ethylene to ethylene oxide, Chem. Eng. Commun., 82 (1989) 229-232. 